\title{
Picturing internal fractures of historical statues using ground penetrating radar method
}

\author{
S. Kadioglu and Y. K. Kadioglu \\ Ankara University, Faculty of Engineering, Department of Geophysical Engineering, 06100 Tandogan/Ankara, Turkey
}

Received: 16 October 2009 - Revised: 3 January 2010 - Accepted: 2 February 2010 - Published: 12 March 2010

\begin{abstract}
The aim of the study is to formulate an approach to the monitoring of internal micro discontiniuties in a hybrid 2-D/3-D image of ground penetrating radar (GPR) data gathered on historical monument groups, and to indicate methodologically rearranging amplitude-color scale and its opacity functions to activate micro fractures in monument groups including three colossal women, three men, and 24 lion statues in Mustafa Kemal ATATÜRK's mausoleum (ANITKABIR) in Ankara, Turkey. Additionally, this paper illustrates the use of petrographic research to describe the monument and its groups. To achieve the aim, data measurements were carried out on the monument groups with spaced $10 \mathrm{~cm}$ profiles and $1.6 \mathrm{GHz}$ antenna.

The 3-D image was transparent 3-D volumes of the GPR data set that highlighted internal micro fractures and cavities in the statues. Rearranging appropriate amplitude-color scale and formulating the opaque of the data sets were the keys to the transparent 3-D data visualizations. As a result, the internal fractures and cavities were successfully visualized in the three women, three men and twenty-four lion statues. Micro fractures were observed particularly at the rim of the vesicular of the rocks under a polarizing microscope.
\end{abstract}

\section{Introduction}

Requirements for maintaining the existing condition of the statues belonging to monuments are different from the requirements of an initial treatment. Many of the problems associated with treatment involve the unavailability of existing information. Treatments are usually expressed by coating and/or vapor barriers, and compatibility with substrate. There is also a need for improved nondestructive methods

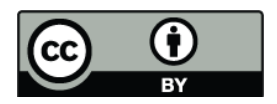

Correspondence to: S. Kadioglu

(kadioglu@eng.ankara.edu.tr) in evaluating the progress of treatments. One of them is the GPR method to evaluate the existence of internal discontinuities such as micro fractures and cavities.

The GPR method has been used successfully for engineering problems. Furthermore, fracture imaging has become an important area of interest (Tsoflias et al., 2004; Kofman et al., 2006; Grasmueck et al., 2005; Kadioglu, 2008). Fractures in any wall, any column, or any statue are far smaller than they are in any shallow subsurface fractures. To determine tiny fractures in any wall, any column or any statue, it is necessary to use higher frequencies, up to $900 \mathrm{MHz}$ rather than the normal frequency ranges used for determining shallow subsurface fractures. On the other hand, different sized fractures seen on the GPR data sections (radargrams) gathered by different frequency ranges have shown the same features. For instance, fractures filled with air and/or moisture commonly cause large reflectivity contrasts resulting in high amplitude GPR reflections, while cemented fractures cause a weaker response. Diffraction hyperbolas are common patterns of vertical or near-vertical fractures and cavities (Grasmueck et al., 2005; Kadioglu 2008). Low-frequency signals are seen just below these hyperbolas (Kofman et al., 2006).

In this paper, we determined and pictured the micro internal fractures and cavities of the three women, three men and twenty-four lion statues in Mustafa Kemal ATATÜRK's mausoleum (ANITKABIR) in Ankara, Turkey (Fig. 1), with the parallel-acquired 2-D GPR profiles on the statues. We pictured the micro fractures on the 2-D radargrams and in the transparent 3-D visualization of 2-D radargrams by activating maximum negative and positive amplitude ranges by displaying a limited color and opaque of the amplitude range.

The mausoleum ANITKABIR, whose construction began in 1944 and was completed in 1953 (Fig. 1), hosts state ceremonies during national festivals, and represents the Turkish people and Ghazi Mustafa Kemal ATATÜRK, the founder of the Republic of Turkey (Fig. 1b). Therefore, the mausoleum is very important for the Turkish people. The

Published by Copernicus Publications on behalf of the European Geosciences Union. 
monument has been constructed in three parts. The first part is an entrance road called the Lion Road, which is $262 \mathrm{~m}$ long and has a total of 24 lion statues located on each side (Fig. 1c). The second part is a ceremonial square while the third one is the Mausoleum (Fig. 1c). There are three colossal men statues in front of the freedom tower on the left side (Fig. 1d) and three colossal women statues in front of the Independence Tower (Fig. 1e) on the right side at the beginning of the Lion Road (http://www.tsk.tr/anitkabir/ anitkabiryerlesim.html). The women statues wear national dresses. The first and the last women together hold a barley wreath, which represents a young and fertile Turkey. The first woman on the left side asks for God's compassion for Atatürk with a bowl in her right hand. The woman in the middle closes her face and cries because Atatürk has died (Fig. 1e). The man on the right side represents a Turkish soldier with his galea and coat, while the man on the left side represents enlightened Turkish youths and men. The man with a costume in the middle represents a Turkish peasant (Fig. 1d). A total of 24 lion statues representing power and peace sit on each side of the Lion Road (Fig. 2).

During maintenance and treatment studies of Anitkabir in 2007, the GPR method and petrography of the statue rocks were incorporated into the process of figuring internal fractures of the statue groups to determine stability state and characteristics of the statues. The petrographic characterization explains mineral composition and physical properties of the statue rocks which helps interpretation of the GPR data.

\section{Petrographic characterization of the monument groups}

Anitkabir was built mainly of travertine with a rare amount of limestone and ignimbrite rocks. White and yellow travertine came from the Pinarbasi district Kayseri and the Eskipazar district of Cankiri, respectively. Different concentrations of $\mathrm{Fe}, \mathrm{Mg}, \mathrm{Cl}$ and $\mathrm{Mn}$ may mean different colors for travertine, ranging from white to yellow, pale green to beige. Although travertine has no black or gray stains on its surfaces, pollution in Ankara has caused black and gray spots on the surface of Anitkabir's travertine building blocks with a thin film of $\mathrm{Pb}$ content.

The rock composition of the monument groups (three women, three men) and twenty-four lion statues of Anitkabir are mainly composed of white travertine from Pinarbasi, Kayseri. The white colored travertine has a banded and spongy texture under the microscope (Fig. 3). It is mainly composed of calcite, aragonite with a rare amount of salt, recrystallized calcite, gypsum and plant relicts. The modal mineralogical composition and physical properties of this travertine are shown in Table 1. Micro fractures have been observed especially at the rim of the vesicular of the rocks under a polarizing microscope.

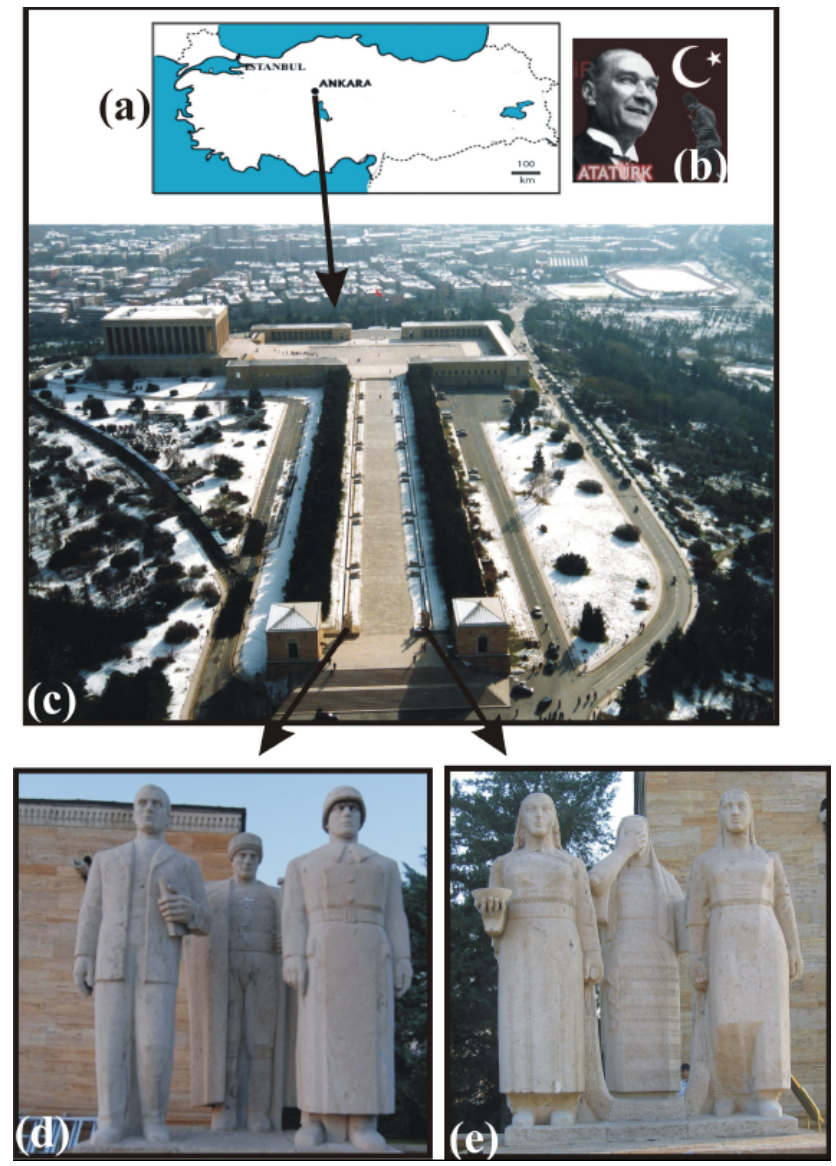

Fig. 1. (a) Location map of the study area, (b) the monument ANITKABIR, Ankara-Turkey, (c) Three colossal men statues at the beginning of the Lion Road, which is the entrance to Anitkabir, on the left side, (d) Three colossal women statues at the beginning of the Lion Road across the man statue group.

\section{GPR data acquisition}

In acquiring GPR data, we divided the colossal women and men statues into several subparts such as skirt or under waist, between waist and neck, arms, trousers, etc. Some parts were divided into extra subparts (Figs. 4, 5, and 6) according to their figures. The body of the first woman was split into two parts called skirt and between waist and neck (Figs. 4a, b and 7), while the body of the second woman was split into four parts called under knee of the left leg, under knee of the right leg, between knee and waist and between waist and neck (Figs. $4 \mathrm{~d}$ and 8). Profiles were spaced with $10 \mathrm{~cm}$ on each subpart and lined with paper band sticker (Figs. 4, 5 and 6). Three profiles spaced with $10 \mathrm{~cm}$ were arranged along the backs of lion statues (Fig. 6). GPR profile data were acquired by RAMAC CU II system with $1.6 \mathrm{GHz}$ shielded antenna on all the monument groups. Transmitter-receiver antenna offset was $0.05 \mathrm{~m}$. Trace spacing was $0.0044 \mathrm{~m}$ and time sampling interval per trace on each profile was $0.0327 \mathrm{~ns}$. 

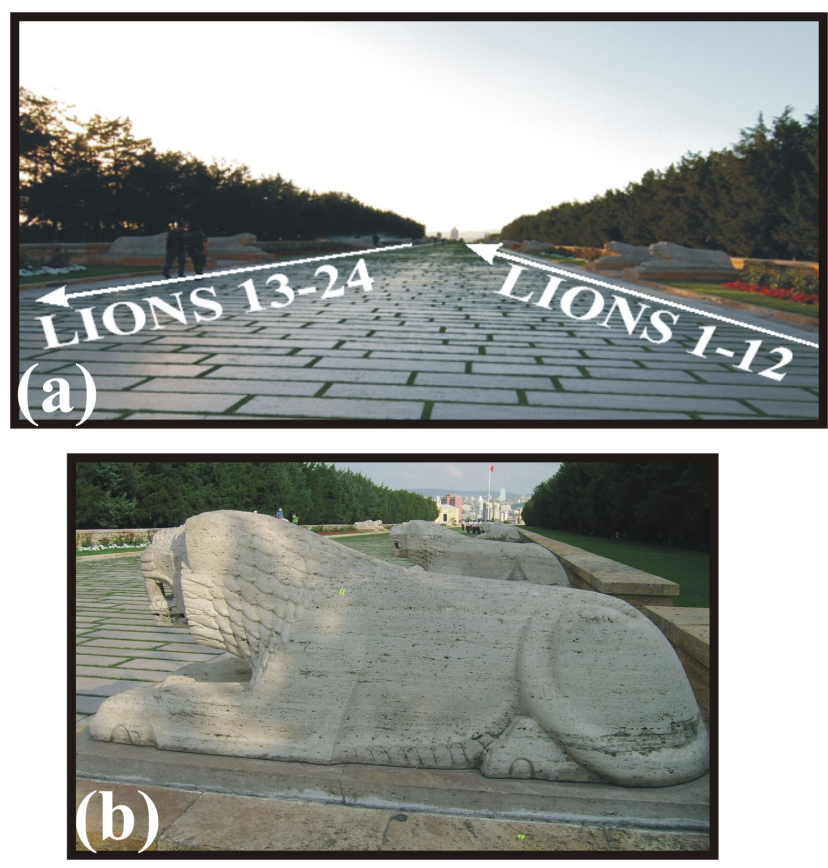

Fig. 2. Lion statue group including 24 lions sitting on what is called the Lion Road at Anitkabir.

Profile tests were carried out to determine the electromagnetic wave velocity of the travertine, and then decide the recording time window according to the approximate thicknesses of the statues.

\section{GPR data processing and transparent 2-D/3-D display of the fractures}

Data processing was performed on the 2-D GPR profile data set with the GPHYZGPR program, developed by Daniels (2000). It included a move start time and a secondorder band-pass Butterworth frequency filter. Amplitude attenuations were balanced by using a linear gain function and average trace subtracting was applied to all profiles. Average electromagnetic (EM) wave velocity of the statues made by travertine rock was calculated by marking on a top and matching one side of the hyperbolas with diffraction patterns throughout the profiles. The matching led to a velocity analysis. The average velocity was determined as $0.11 \mathrm{~m} / \mathrm{ns}$ to convert from time to thickness starting from front to back of the statues. Kirchhoff migration was applied. Finally 3-D data volumes were constructed by lining processed 2-D profile data set relating to each part of the statues to correlate fractures from each profile. The 3-D data volume provided an interactive interpretation.

It was known that the air filled fractures and cavities had a maximum reflection coefficient and a maximum wave velocity (Tsoflias et al., 2004; Kofman et al., 2006; Grasmueck et al., 2005). We applied an approximation to eliminate the
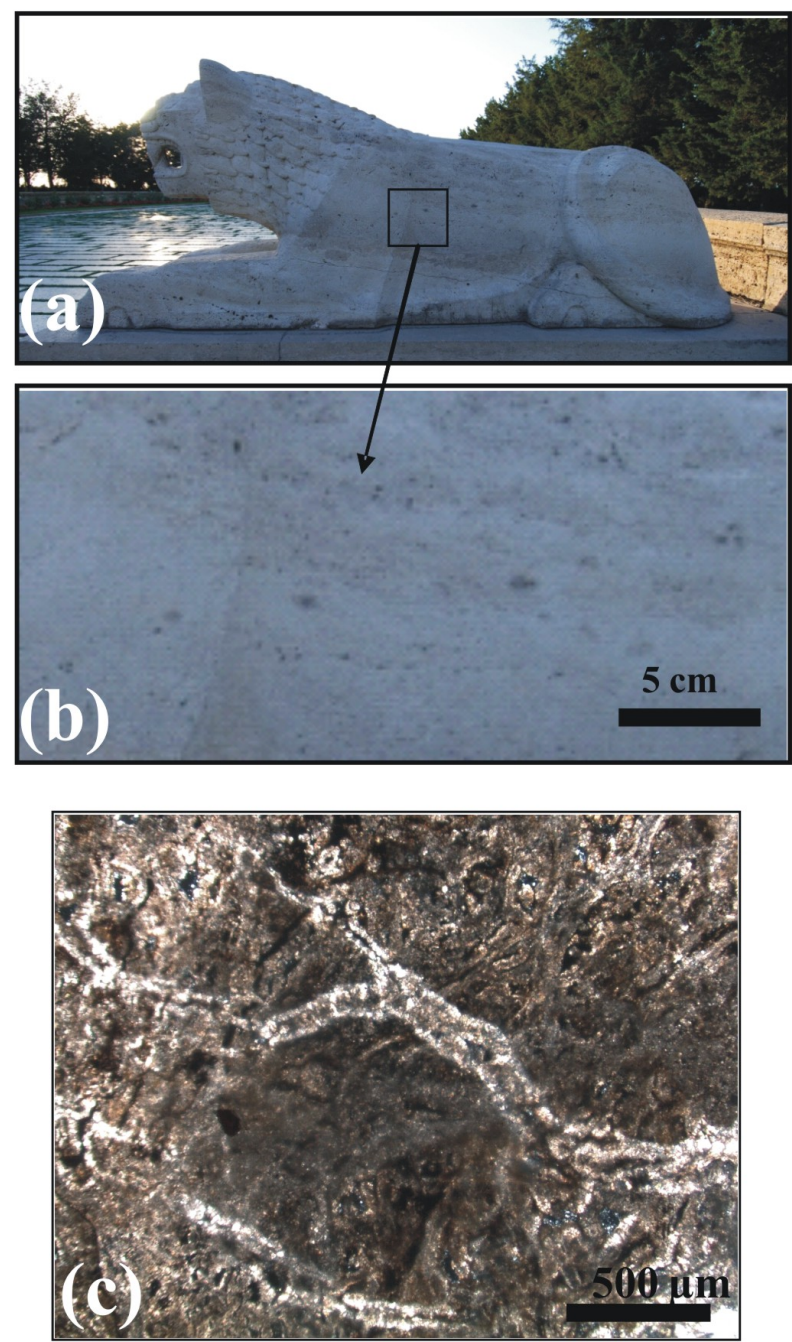

Fig. 3. (a) A lion statue, (b) close view to surface of lion and (c) microphotograph of white-colored travertine.

weak reflections, which represent cemented rock characterization (Grasmueck et al., 2005), and to activate the fractures and cavities represented with strong reflections/diffractions on the radargrams (2-D GPR profile data sections) by assigning a new color scale for the amplitude range of the processed profile data set (Fig. 7) with a new amplitude-color function instead of linear amplitude-color function (Kadioglu, 2008).

Figure $7 \mathrm{a}$ indicates a radargram which is gathered on the fourth profile of the skirt part of the first woman statue with a selected linear amplitude-color range function (Fig. 7b). Figure $7 \mathrm{c}$ displays the same radargram which reveals all anomalies including fractures, cavities and mineral compositions with a new constructed amplitude-color range function on Fig. 7d, which divides amplitude-color range into two parts as negative and positive amplitudes symmetrically; increases the maximum amplitude ranges represented by a constant black and red color function and restricts color linearity of 
Table 1. Modal mineralogical composition and physical properties of white-colored travertine in Anitkabir.

\begin{tabular}{ll}
\hline Mineral Composition & Calcite (54\%) and Aragonite (31\%) \\
\hline Alteration Products & $\begin{array}{l}\text { Recrystalized calcite (13.5) and rarely } \\
\text { gypsum and halite }(1.5 \%) \\
\text { Color }\end{array}$ \\
White \\
Hardness & $3 \mathrm{Mohs}, 52.8 \mathrm{Schmidt}$ \\
Unit Volume Weight & $2.52 \mathrm{gr} / \mathrm{cm}^{3}$ \\
Porosity Ratio (\%) & $9.8 \pm 2.180$ \\
Cracks Ration (\%) & 3.4 \\
Alteration Ratio (\%) & 2.5 \\
\hline
\end{tabular}

the rest amplitude ranges. Figure $7 \mathrm{e}$ represents our simplified radargram approximation with second new constructed color range function of the amplitudes (Fig. 7f), on the same radargram, where constant black color was assigned for maximum negative amplitude range and constant red color was assigned for maximum positive amplitude range and constant green color for the rest (Fig. 7f). Figure 8 displays radargrams between the profiles 1 and 5 of the skirt part of the first woman statue with the new approximation. The color limitation made only fractures and cavities visible on the radargrams (Figs. 7e and 8).

Our second approximation in this paper was about transparent 3-D visualization of the profile data set by constructing a new opacity function instead of solid 3-D image with linear opacity function (Fig. 9). Horizontal axes of these opacity functions represent amplitude-color scale of the GPR data set, and vertical axes represent opacity coefficients. Maximum positive and maximum negative amplitude ranges (represented by the red and black colors) were dominated and others (green color) were eliminated using zero opacity by the new opacity function (Fig. 9b).

Firstly, the 3-D GPR data volume of the skirt part of the first woman statue was shown by the new arranged amplitude-color range (Fig. 7f) and a linear opacity function (Figs. 9a and 10). The horizontal $x$-axis of Fig. 10 indicates the distance along the measuring profile. The horizontal $y$ axis represents the profile sequence. The vertical axis indicates thicknesses of statues from the front surface to the back surface of the skirt of the statue. Secondly, the same data volume was displayed again with the new amplitudecolor scale (Fig. 7f) and the new constructed opacity function (Figs. 9b and 11). The fractures in all statue groups were displayed with constructed transparent 3-D profile sub-blocks as Fig. 11 (Figs. 12, 13 and 14).
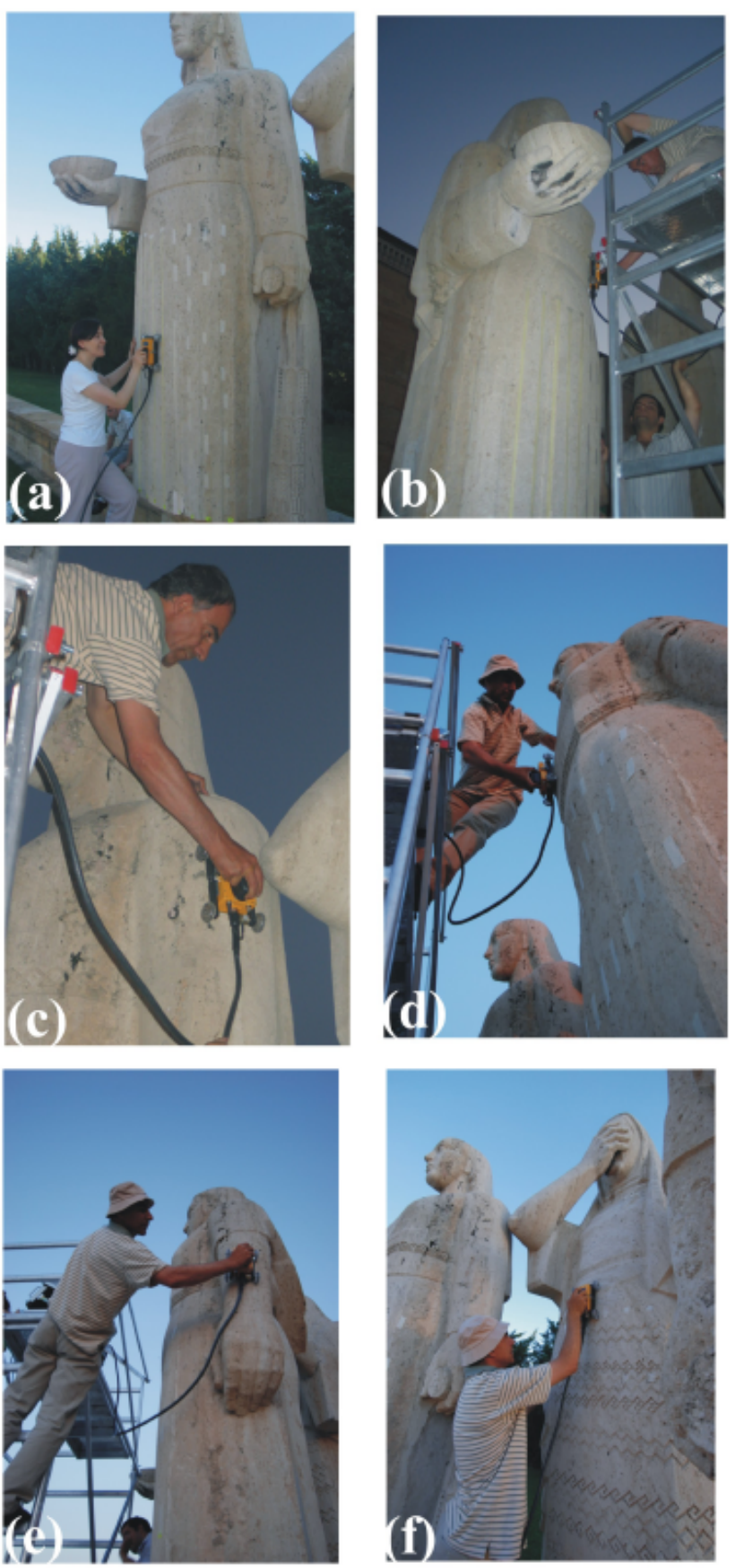

Fig. 4. Data acquisitions of the first woman statue (a) on the skirt, (b) between the waist and the neck, (c) on the left arm, (d) data acquisition of the second woman statue between the waist and the neck and (e) on the left arm, (f) on the skirt of the third woman statue. 

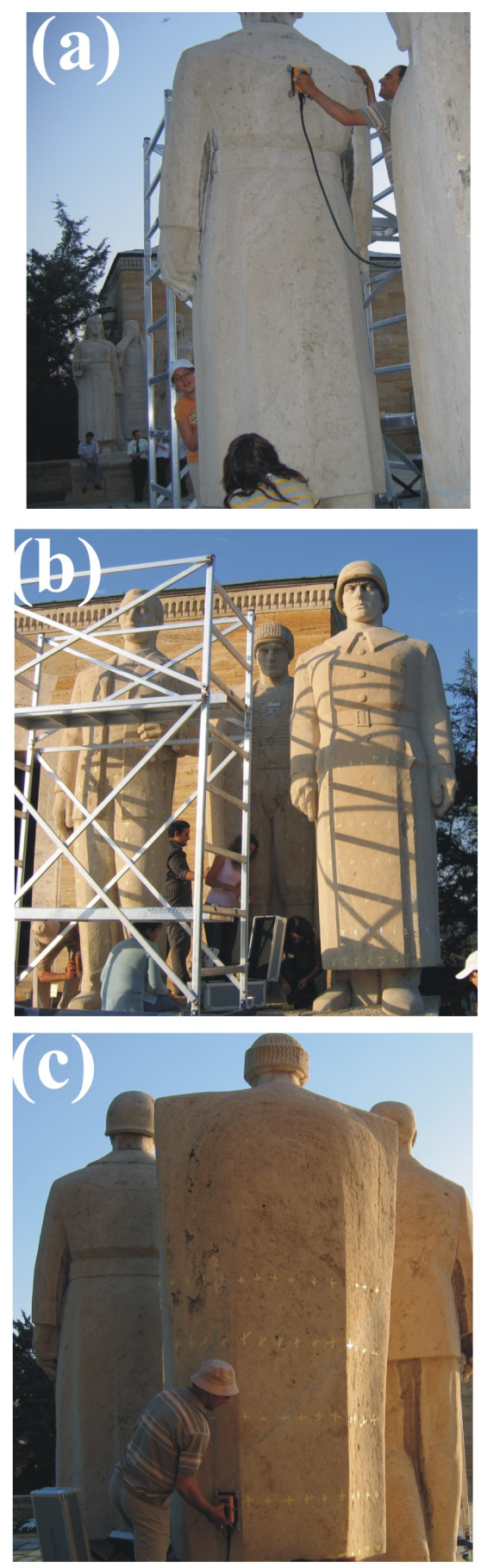

Fig. 5. (a) Data acquisitions on the back of the first man statue between the waist and the neck, (b) on the second man statue, and (c) below the waist of the back of the third man statue.

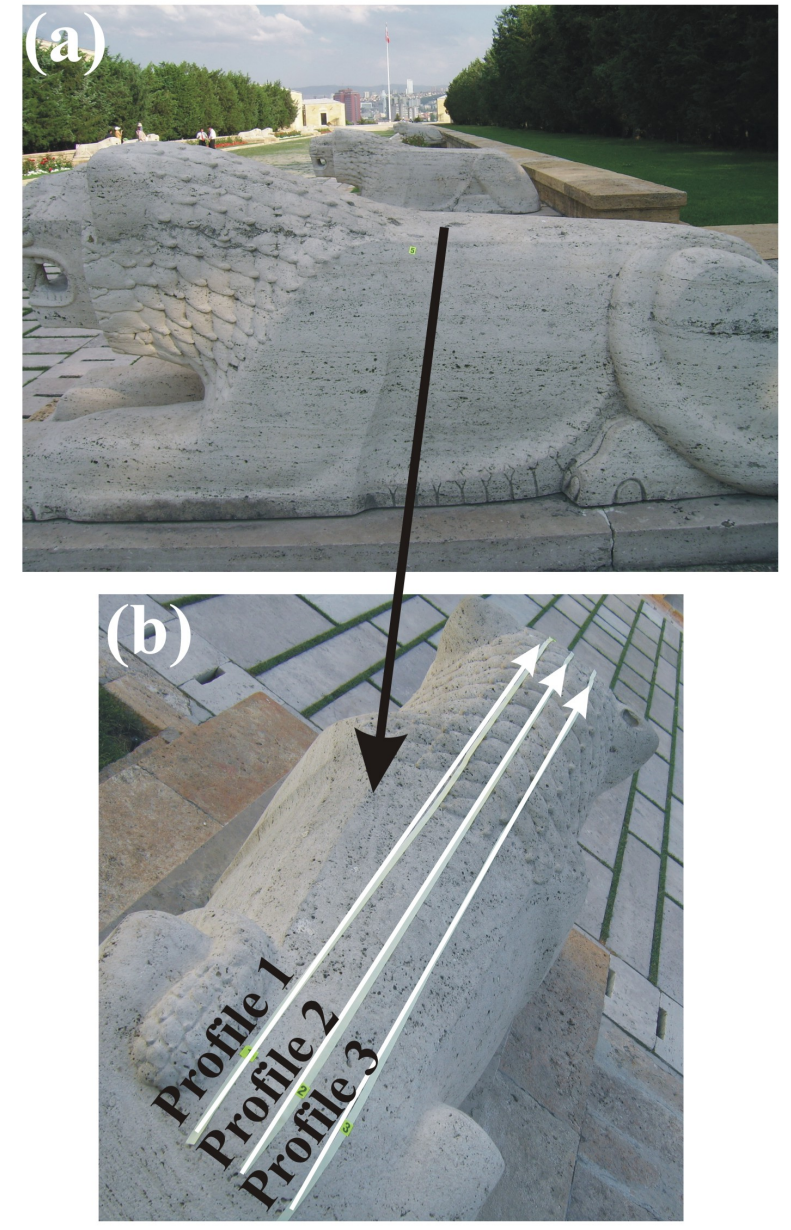

Fig. 6. Data acquisitions of the lions (a) the third lion and (b) three parallel profiles spaced $10 \mathrm{~cm}$ on the back of the third lion. 


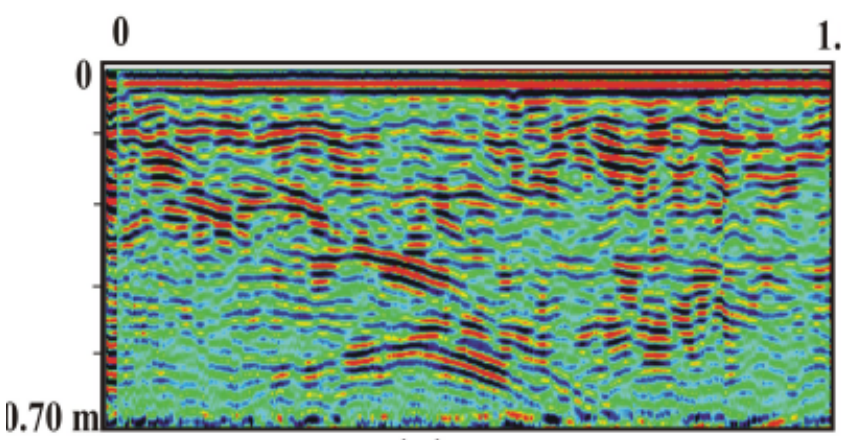

(a)

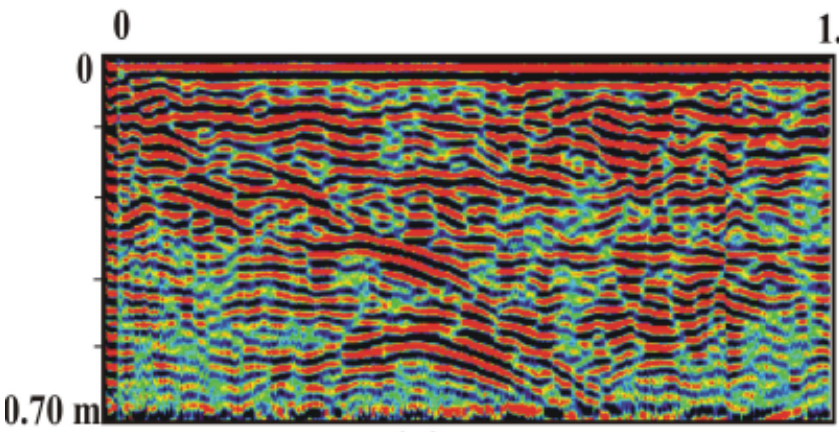

(c)

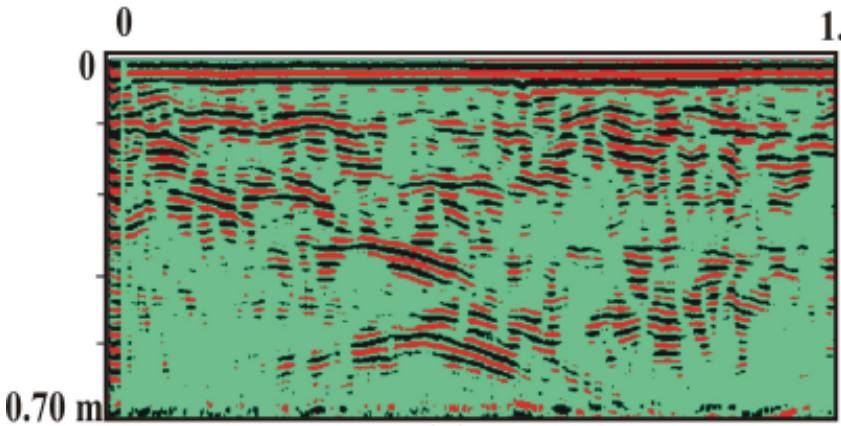

(e)
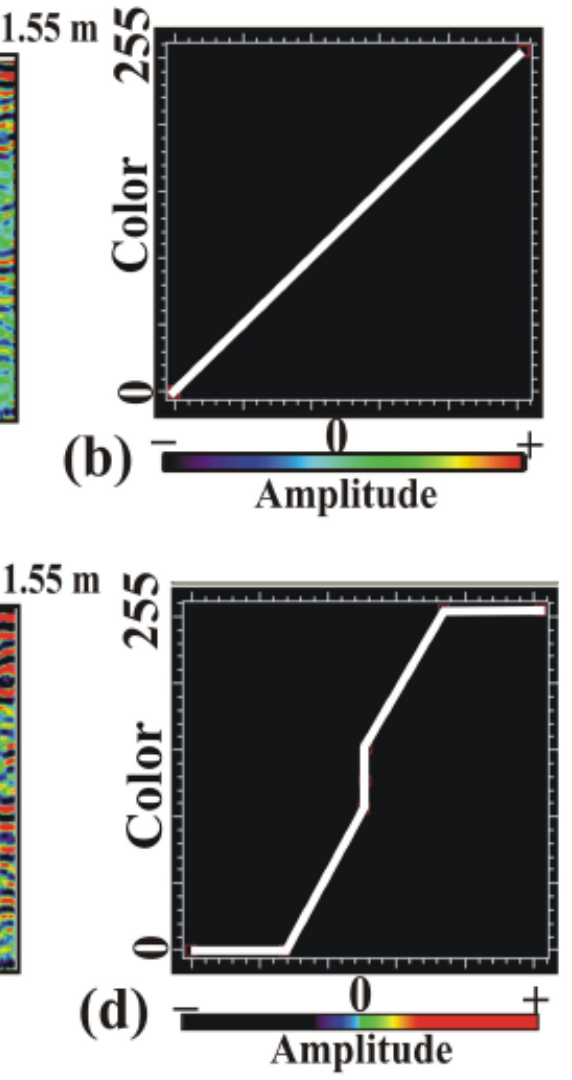

$1.55 \mathrm{~m}$

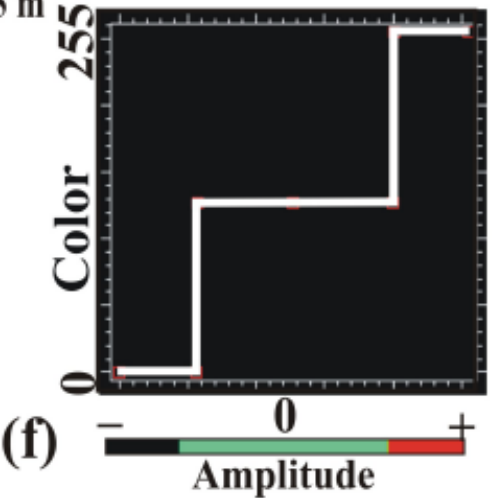

Fig. 7. (a) Radargram of the fourth profile on the skirt part of the first woman statue with (b) linear amplitude-color scale; (c) radargram of the same profile displaying all features of the statues with (d) the new arranged amplitude-color scale which activates all amplitudes (e) radargram of the same profile pointing the fractures and cavities with (f) the new arranged amplitude-color scale which activates only limited maximum negative and positive amplitude range. 

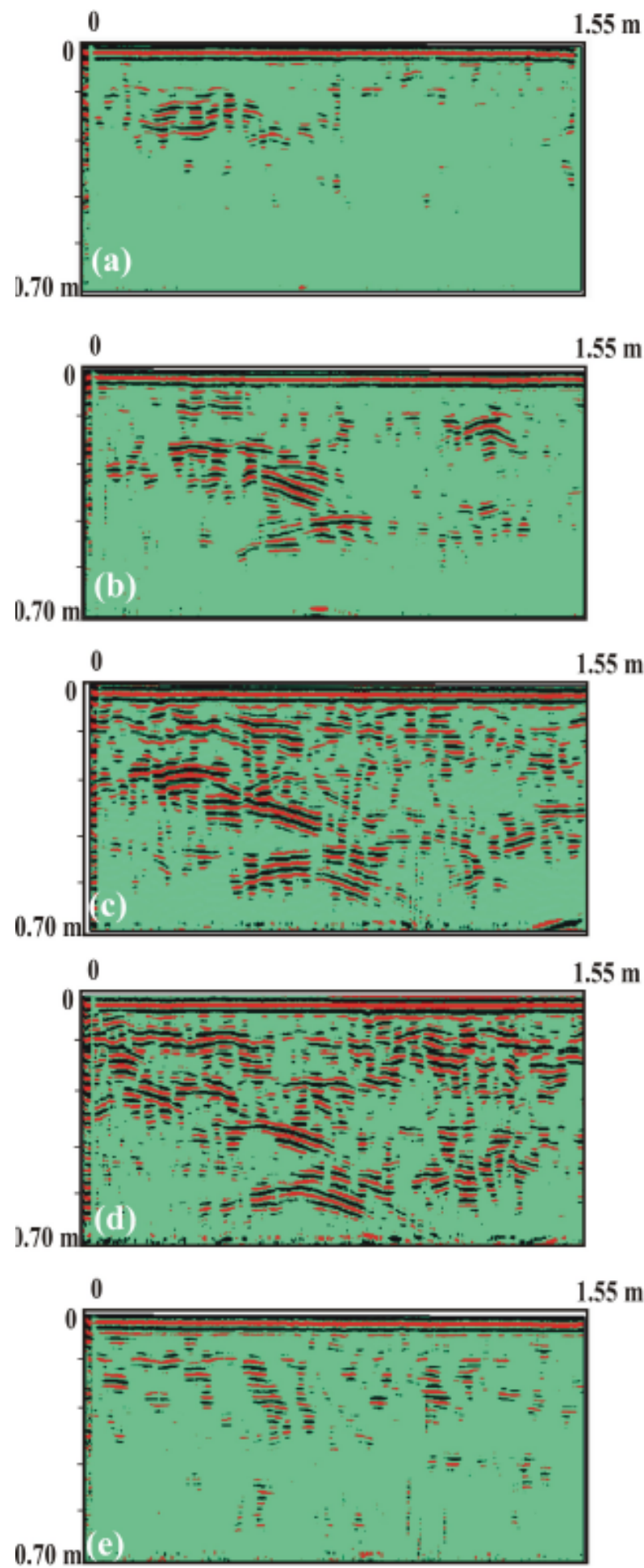

Fig. 8. The radargrams of (a) profile 1, (b) profile 2, (c) profile 3, (d) profile 4 and (e) profile 5 of the skirt part of the first woman statue with new amplitude-color approximation. 


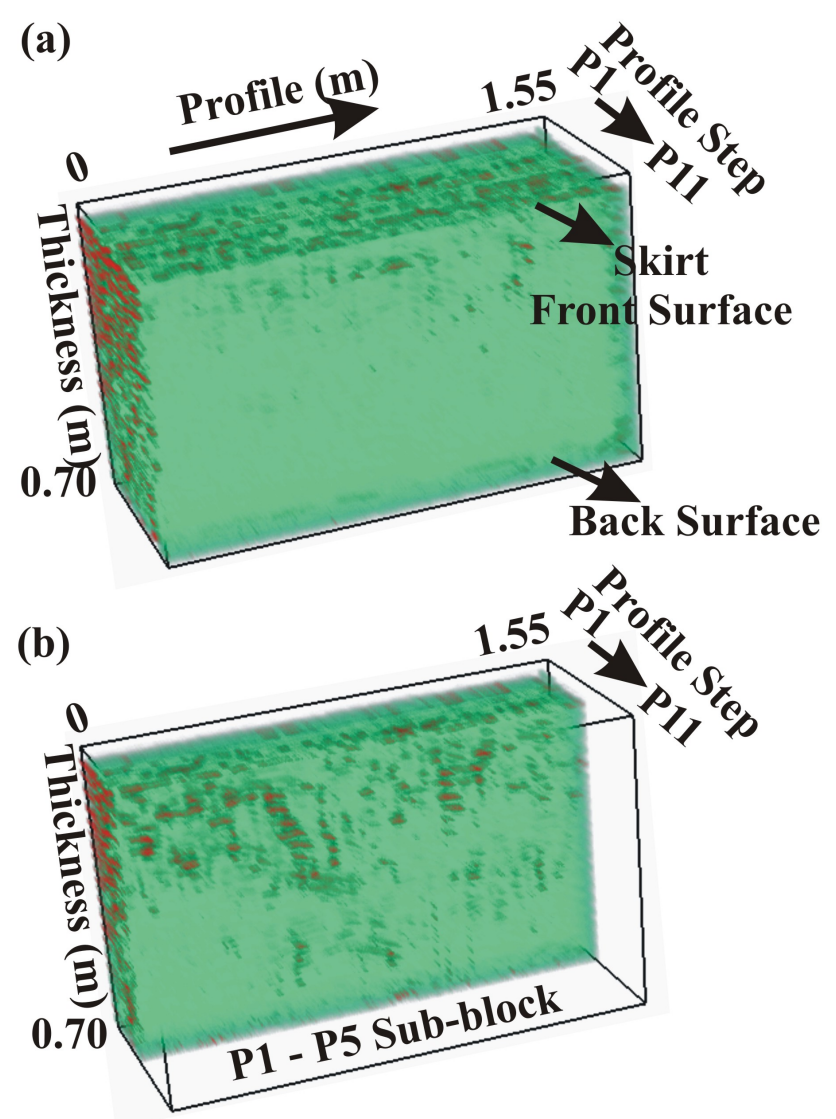

Fig. 10. (a) A solid 3-D full data block and (b) a solid 3-D data sub-block between profile 1 and profile 5 of the skirt part of the first woman statue with linear opacity function (Fig. 9a).

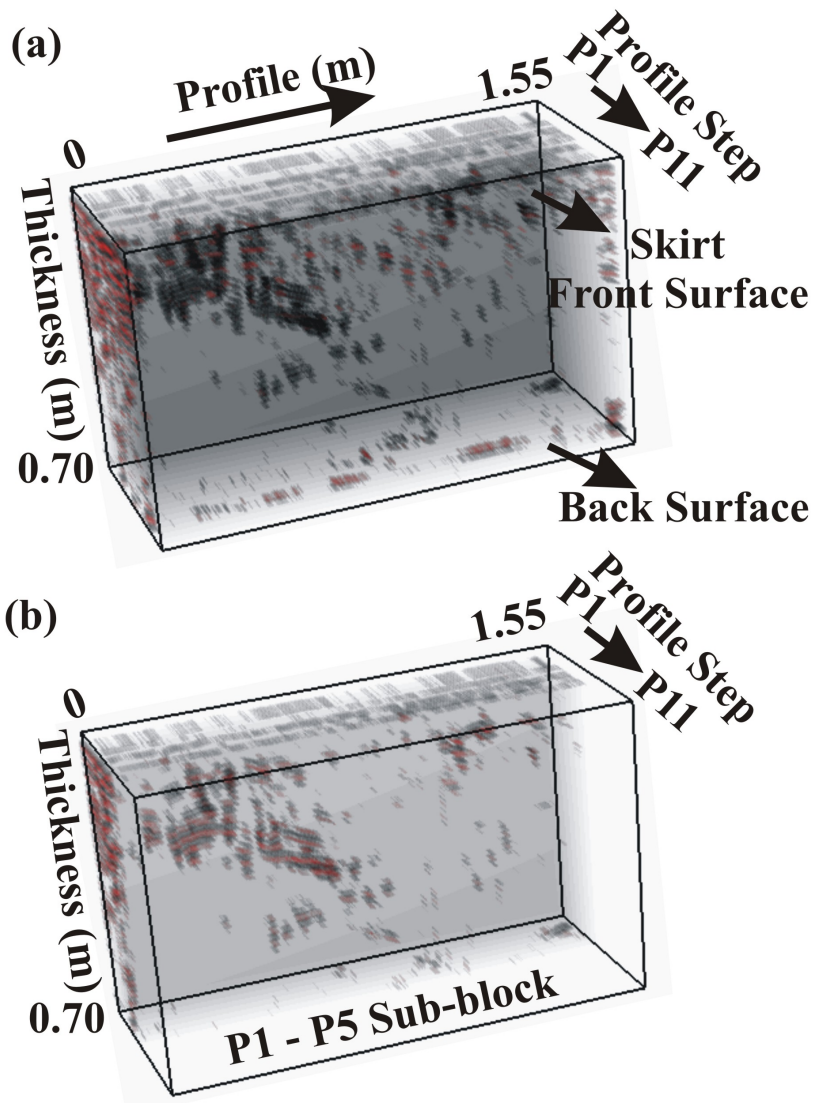

Fig. 11. (a) A transparent 3-D full data block and (b) a transparent 3-D data sub-block between profile 1 and profile 5 of the skirt part of the first woman statue with new opacity function approximation (Fig. 9b). 


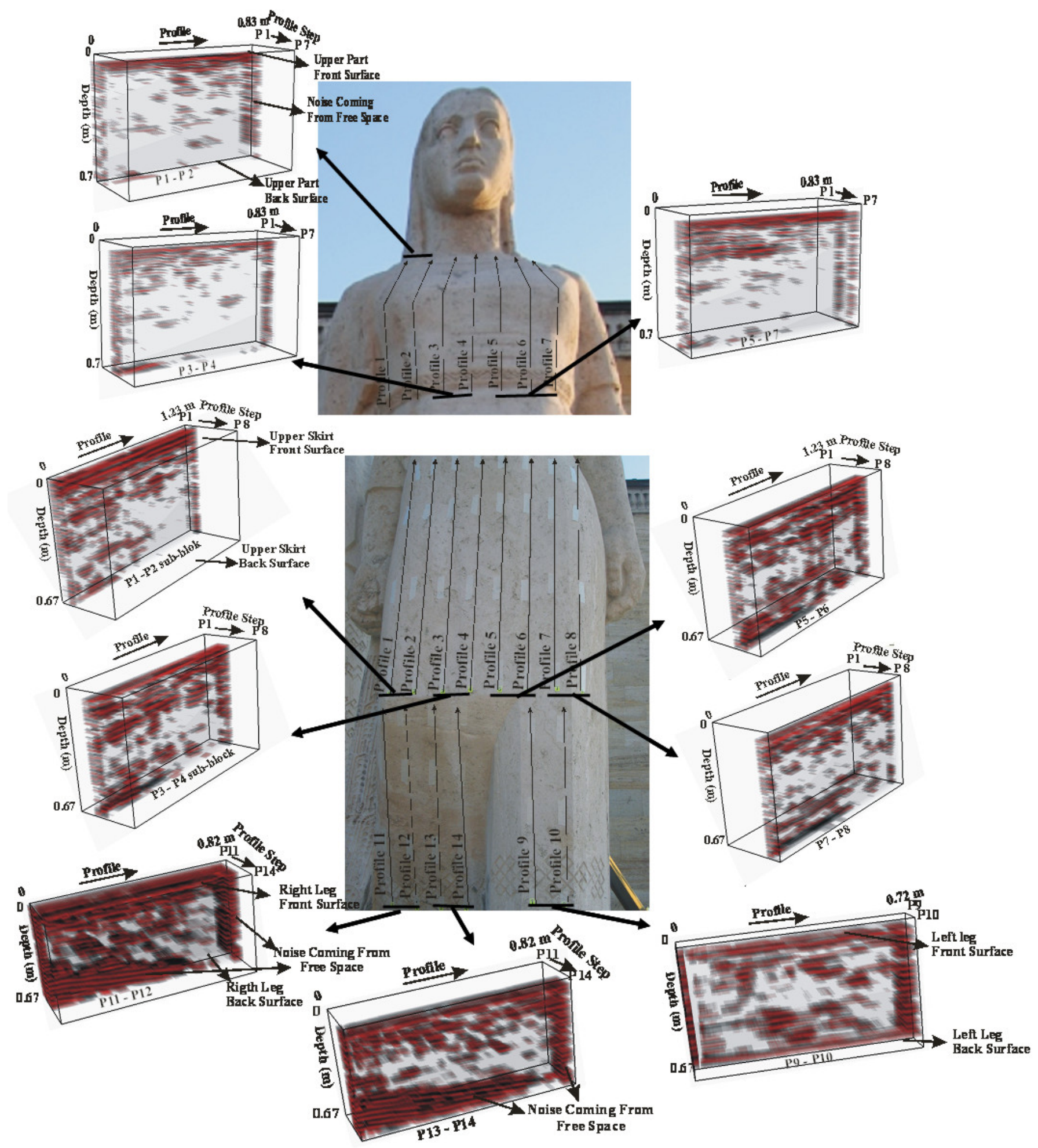

Fig. 12. The transparent 3-D visualization results with the fractures and large cavities of the second woman statue. 


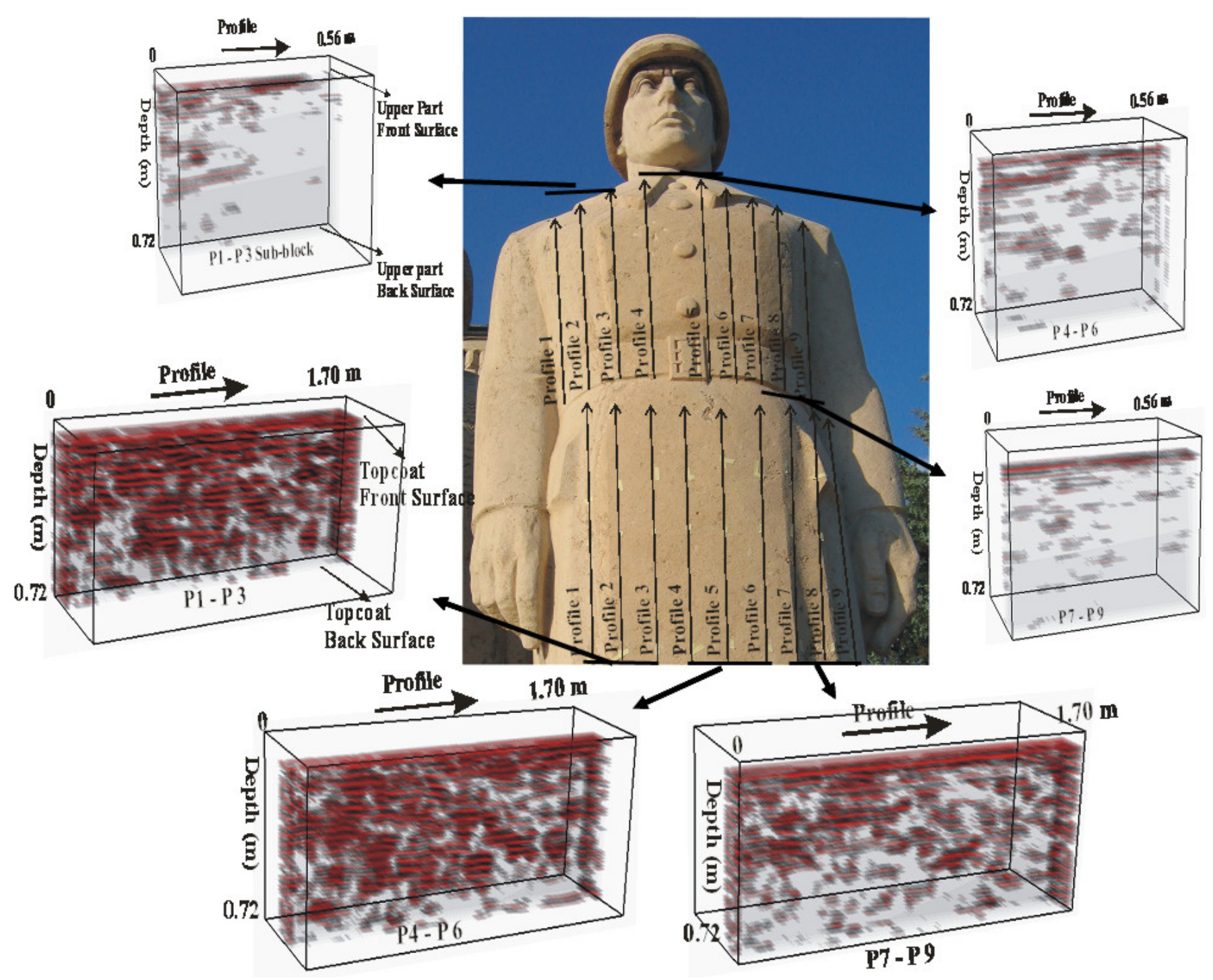

Fig. 13. The transparent 3-D visualization results with the fractures and large cavities of the first man statue. 


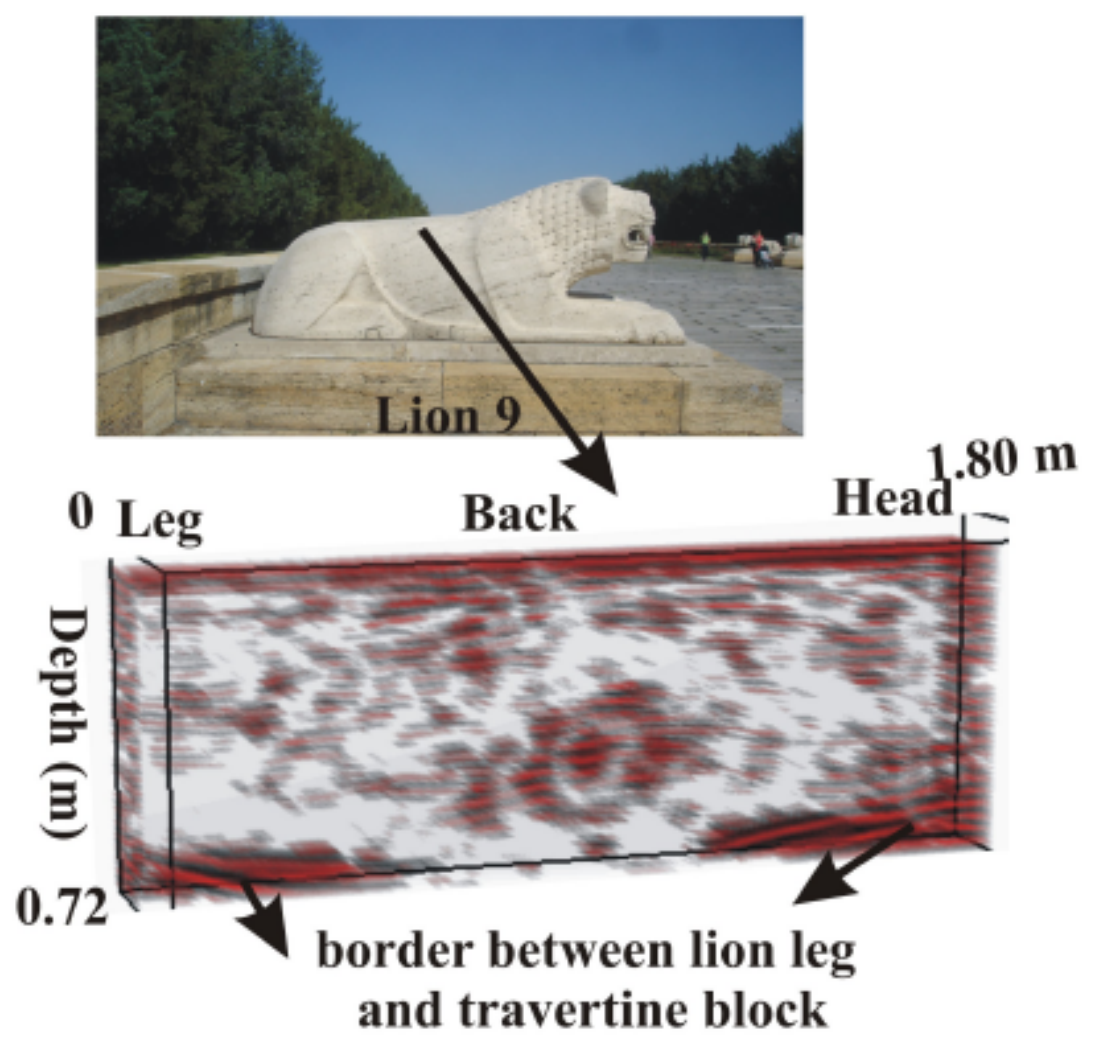

(a)

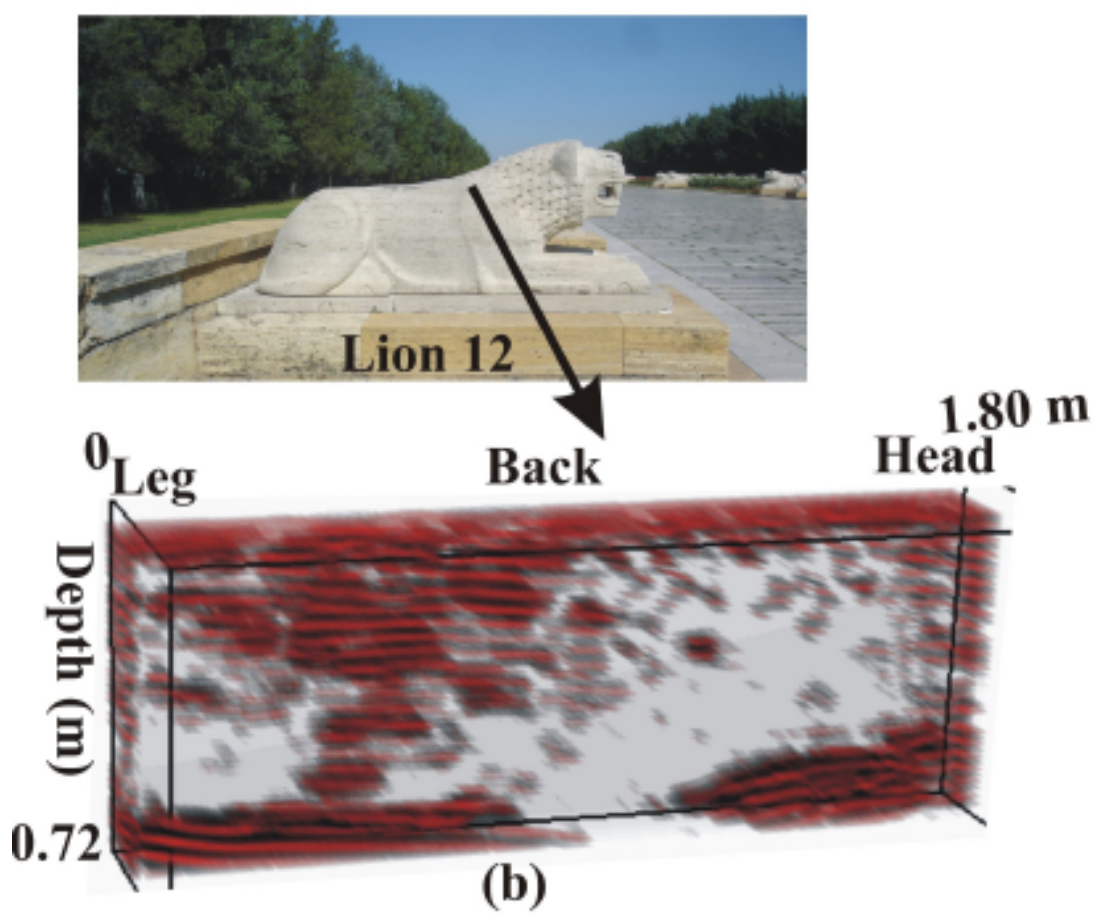

Fig. 14. (a) The transparent 3-D visualization results with the fractures and large cavities of the ninth lion statue and (b) the twelfth lion statue. 


\section{Results and interpretation}

Interactive transparent 3-D visualizations of the GPR data volumes were carried out for each part of the three monumental women, three monumental men, and 24 lion statues. We pictured interactive transparent 3-D visualization results of the second woman, first man and two lion statues with Figs. 12, 13 and 14, respectively. We displayed the transparent profile sub-volumes including two or three profiles in their full 3-D data volumes to increase the sensitivity of the visualization. Transparent 3-D GPR data monitoring displayed interior fractures and natural cavities of the colossal statues. This monitoring was the interpretation. The GPR data results were supported by petrographic and physical properties of the statues travertine rock (Table 1.) with the mineral composition, the porosity ratio and cracks ration of the rock.

The body of the second woman statue was divided into four parts because her skirt had a sharp twist at the knee (Fig. 12). The first part was the right leg twisted under the knee and the second part was the left leg under the knee. The third part was between the knee and the waist, and the fourth part was between the waist and the neck (Fig. 12). There were four profiles on first part, $0.82 \mathrm{~m}$ long, while there were two profiles on the second part. Similarly, eight profiles on the third part, and seven profiles on the fourth part were exhibited by interactive transparent 3-D data sub-blocks including two or three profiles to observe particularly very small fractures and cavities seen with red-black colors

It was seen that inclined signals under side of the 3-D subdata blocks of the first part were coming from free space (on the left bottom corner at the Fig. 12), and short repeated signals in the beginning and/or in the ending of the 3-D sub-data blocks were also coming from free space because of the antenna situation (Fig. 12). All parts included mostly natural cavities of the travertine rock. There were a few fractures along between the profiles 1 and 2 , and between profiles 5 and 6 . These fractures were more noticeable near the knee of the third part (upper skirt) of the second woman statue (Fig. 12). They might have important implications for stability in the future. The sub-block of the fourth part, from waist to neck, including profiles 5, 6 and 7, were in the same state in the woman statue. Other sub-blocks indicated very small native cavities much clearly. Gathering the profile data, the body of the first monumental man statue was divided into two parts, namely under the waist and upper the waist of the topcoat of the statue. The results of the 3-D imaging were shown with Fig. 13. There was an abundance of large native cavities under the waist and some of them seemed to be short and independent fractures between profiles 1-3. The topcoat was clear. However, there were some fractures near the waist of the front surface of the man coat along the profile direction between profiles 1 and 6 . The results of the 3-D imaging of the lion 9 and lion 12 were shown on the Fig. 14. While
Lion 9 had an abundance of small native cavities, lion 12 had horizontal fractures along the back and from the back to its tummy.

\section{Conclusions}

Air-filled fractures and cavities in the travertine had a maximum reflection coefficient. Therefore, after processing, a simplified amplitude-color range was assigned for maximum positive and negative polarities and the rest. The color limitation made small scale fractures visible on the radargrams. However, solid 3-D block data with linear opacity could not image the fractures and cavities exactly. A new opacity function was constructed, which dominated maximum positive and negative amplitudes and eliminated other irrelevant amplitudes. Therefore, transparent 3-D image of the GPR data was obtained. Interactive visualizations of the fractures with their thickness and directions were done by using sub-blocks of the transparent 3-D volume. Transparent 3-D imaging results were the interpretation of the locations of the fractures. The GPR results were supported by vesicular textures within travertine. Mapping fractures and cavities in the monumental statue groups could indicate their stability evaluation and showed the best way to minimize restoration costs.

Acknowledgements. The authors would like to thank the military authorities at ANITKABIR, Earth Sciences Application and Research Center (YEBIM) of Ankara University for supporting the projects, as well as Prof. Jeffrey DANIELS (Ohio-State University) for allowing us to use his GPHYZGPR IDL 5.5 program for GPR data processing. The authors also thank the MSc student group of the Ankara University Geophysical and Geological Engineering Departments for helping us in data gathering.

Edited by: L. Eppelbaum, N. Masini, and F. Soldovieri Reviewed by: two anonymous referees

\section{References}

Daniels, J. J.: Ground penetrating radar for imaging archaeological objects in the subsurface, Proceedings of the New Millennium International Forum on Consideration of Cultural Property, Kongju, Korea, 247-265, 2000.

Grasmueck, M., Weger, R., and Horstmeyer, H.: Full-resolution 3 D GPR imaging, Geophysics, 70(1), K12-K19, 2005.

Kadioglu, S.: Photographing Layer Thicknesses and Discontinuities in a Marble Quarry with 3-D GPR Visualisation, J. Appl. Geophys., 64, 109-114, 2008.

Kofman, L., Ronen, A., and Frydman, S.: Detection of model voids by identifying reverberation phenomena in GPR records, J. Appl. Geophys. , 59(4), 284-299, 2006.

Tsoflias, G. P., Gestel, J-P. V., Stoffa, P. L., Blankenship, D. D., and Sen, M.: Vertical fracture detection by exploiting the polarization properties of ground-penetrating radar signals, Geophysics, 69(3), 803-810, 2004.

Turkish General Staff (TSK): http://www.tsk.tr/anitkabir/ anitkabiryerlesim.html. 